\title{
LEITURA DAS REGIONALIDADES CULTURAIS ENTRE O PAMPA E O SERTÃO NA LITERATURA BRASILEIRA
}

\author{
READING OF CULTURAL REGIONALITIES BETWEEN \\ PAMPA AND THE SERTÃO IN BRAZILIAN LITERATURE
}

\author{
Graciele Macedo Pedra ${ }^{23}$ \\ Priscila Monteiro Chaves ${ }^{24}$
}

Resumo: $O$ presente ensaio se propõe a analisar os contos $A$ terceira margem do rio do escritor mineiro Guimarães Rosa, Travessia de Sérgio Faraco e O anjo da Vitória de João Simões Lopes Neto, escritores gaúchos. Foi observado, a partir da narrativa de três crianças, a tentativa de enxergar heróis nas figuras: o pai que buscou refúgio em uma canoa no rio, a busca pela sobrevivência do tio marginalizado e a morte precoce do padrinho na guerra. Os autores, através de seus heróis fragilizados, abordam de maneira particular o drama essencial, entre si mesmos e o mundo, através da imaginação das crianças que se envolvem com o arquétipo de seus heróis românticos. Considerando as referenciadas temáticas, ditas universais, algumas questões acerca da literatura regional foram ponderadas.

Palavras-chave: arquétipos; crianças; universalidade; literatura regional.

Abstract: This essay proposes to analyze the tales A terceira margem do rio of the writer Guimarães Rosa, Travessia of Sérgio Faraco and O Anjo da vitória of João Simões Lopes Neto. It was observed from the narrative of three children, the attempt to see heroes in the figures: the father who sought refuge in a canoe in the river, the search for the survival of the marginalized uncle and the early death of the godfather in the war. The

\footnotetext{
${ }^{23}$ Graduação em Licenciatura em Letras Português e suas respectivas Literaturas. Universidade Federal de Pelotas, Brasil. Email: pedragraciele86@gmail.com

24 Doutoranda do Programa de Pós-Graduação em Educação da Universidade Federal de Pelotas, Graduação em Licenciatura em Letras Português/Francês pela mesma Universidade, Brasil. Email: pripeice@gmail.com
} 
authors, through their fragile heroes, approach in a particular way the essential drama between themselves and the world through the imagination of children who engage with the archetype of their romantic heroes. Considering the thematic references, so-called universal ones, some questions about the regional literature were considered.

Key words: archetype, children, universality, regional literature.

\section{Considerações iniciais}

A obra de João Simões Lopes Neto, Contos Gauchescos, que traz o conto $\mathrm{O}$ anjo da vitória, apresenta a crônica histórica de um evento verídico da história da Província, em que a subjetividade da personagem principal Blau Nunes ficcionaliza a Batalha de Ituzaingo. Através da narrativa do menino com seu bichará, com no máximo dez anos, que já acompanhava o padrinho na guerra, nos deparamos com um tom épico, que mitifica o passado.

Simões é inserido pela crítica literária dentro do campo geral denominado regionalismo, mas, segundo Flávio Loureiro Chaves no Pequeno Dicionário de Literatura do Rio Grande do Sul, Contos Gauchescos possui ao mesmo tempo uma perspectiva regionalista e uma visão de mundo ampla e universal.

Alfredo Bosi, ao tratar da obra do escritor, diz que nem toda literatura regionalista perdeu-se nos extremos do precioso ou do banal, e que a obra de Lopes Neto é resultado de um aproveitamento literário das matrizes regionais que alcançou notáveis efeitos estéticos. Nas palavras do autor,

[...] seus contos fluem num ritmo tão espontâneo, que o caráter semidialetal da língua passa a segundo plano, impondo-se a verdade social e psicológica dos entrechos e das personagens (BOSI, 1994, p. 212).

Dando continuidade a uma tradição de escritores que têm por objetivo criar uma identidade em suas obras, para o povo local, Simões consegue desvencilhar-se da mitologia do gaúcho e 
evidenciar a individualidade e a psicologia das suas personagens, sobressaindo à exaltação do regionalismo.

Esse, o cavalo dele não dava de rédea para trás, não! Esse, quando havia fome, apertava o cinto, com os outros e riase. Esse, dormia como quero-quero, farejava como cervo e rastreava como índio...; esse, quando carregava, era como um ventarrão, abrindo claros num matagal.

Com esse... castelhano se desguaritava por essas coxilhas o mesmo que bandada de nhandu, corrido a tiro de bolas!... Era o Anjo da Vitória, esse (LOPES NETO, 1976, p. 50).

O espaço do conto é constituído como uma continuação do ser que o habita, então nasce a associação entre homem e natureza, indissociáveis no universo simoniano, situando as personagens no seu espaço existencial e respeitando-as. Desse modo, o homem encontra a si mesmo e torna-se capaz de entender o mundo e, na eternidade de um passado perdido, as gerações sustentam o mito do gaúcho.

As cousas da peleia não sei, porque era menino e não guardava as conversas dos grandes; o que eu queria era haraganear. $\mathrm{O}$ meu padrinho era um gaúcho mui sorro e acostumado na guerra, desde o tempo das Missões, e que mesmo dormindo estava com meio ouvido, escutando, e meio olho, vendo...; mesmo ressonando não desgrudava pelo menos dois dedos dos copos da serpentina... e depois nos deitamos nos pelegos, com os pingos pela rédea, maneados: ele, armado, mateando; eu, enroscadito no meu bichará... (LOPES NETO, 1976, p. 49).

O conto A terceira margem do rio, de João Guimarães Rosa, em suas Primeiras Estórias, nos apresenta a narrativa do fracasso de um menino que não teve coragem de tomar o lugar do pai, que se refugiou em uma canoa no rio. Observamos o segredo de uma alma através das águas que se projetam em suas três margens. 
Sem alegria nem cuidado, nosso pai encalcou o chapéu e decidiu um adeus para a gente. Nem falou outras palavras, não pegou matula e trouxa, não fez alguma recomendação. O rumo daquilo me animava, chega que um propósito perguntei: - "Pai, o senhor me leva junto, nessa sua canoa?" Ele só retornou o olhar em mim, e me botou a benção, com gesto me mandando para trás. Nosso pai entrou na canoa e desamarrou, pelo remar. E a canoa saiu se indo a sombra dela por igual, feito um jacaré, comprida longa (ROSA, 2005, p. 78).

A alquimia, operada por Rosa, foi tema da crítica, desde a metamorfose que o colocou no centro da ficção brasileira. Desse modo, a narrativa corrobora com o fato de que a palavra é um feixe de significações, o signo estético é portador de sons e de formas, que desvendam as relações íntimas, assim o conflito entre o eu/herói e o mundo resolve-se mediante o pacto do homem com a própria origem das tensões.

No universo de Guimarães, a linguagem do mito rompe as amarras espaço temporais, onde em absoluto silêncio resiste ao tempo, imagem da permanência no fluir eterno das águas. $\mathrm{O}$ sujeito e o objeto opõem-se na aparência, mas no fundo partilham de algo mutável: o devir. $\mathrm{O}$ aporte de sua obra está no limite entre o real e o surreal, explorando as dimensões pré-conscientes do ser humano.

A gente teve de se acostumar com aquilo. Às penas, que, com aquilo a gente mesmo nunca se acostumou, em si, na verdade. Tiro por mim, que, no que queria, e no que não queria, só com nosso pai me achava: assunto que jogava para trás meus pensamentos (ROSA, 2005, p. 79).

Construtor de uma linguagem peculiar, Rosa enriqueceu o português literário, causando dúvidas e admiração no seu leitor. A interpretação de seus contos está ainda em aberto, no vaivém de memórias e reflexões que consistem em momentos, presentes no texto, que são capazes de estreitar os laços com o leitor. 
Sem fazer véspera. Sou doido? Não. Na nossa casa, a palavra doido não se falava, nunca mais se falou, os anos todos, não se condenava ninguém de doido. Ninguém é doido. Ou, então, todos. Só fiz, que fui lá. Com um lenço, para aceno ser mais. Eu estava muito no meu sentido (ROSA, 2005, p. 81).

Finalizando esta seção, é cogente apontar que a obra de Sergio Faraco ordena-se em três grandes vertentes: o homem urbano em sua fragmentária complexidade, vítima dos desencontros; a vida do campo - segurada em vórtices de paixões primárias, mas nem por isso destituídas de sensibilidade e o universo fluido da infância e da adolescência, que transparece como um estágio de encantamento - e, simultaneamente, de instigantes experiências existenciais, a última será abordada com maior ênfase no texto.

$\mathrm{Na}$ obra Contos Completos, o conto Travessia aborda a renovação de um imaginário sobre a tradição e a história dos antepassados que submetendo-se a muitos perigos, encontravam a sua chance de sobrevivência no contrabando de pequeno porte. A narrativa apresenta a estreia do menino nessa prática, juntamente com o tio, na tentativa de atravessar algumas encomendas no Rio Uruguai.

- Essa é a vida - repetiu Tio Joca.

Teso, imóvel, ele olhava para o rio, para a sombra densa do rio, os olhos deles brilhavam na meia-luz da popa e a gente chegava a desconfiar que ele estava era chorando. Mas não, Tio Joca era um forte. Decerto apenas vigiava, na esteira de borbulhas, o trajeto da chalana vazia (FARACO, 2011, p. 49).

As tramas revelam uma visão de esperança. As personagens, movidas pelo desejo de acertar, acabam por envolverse com suas inerentes debilidades que podem incidir no erro, mas nunca à degradação. Procurando entre um passado de conquistas 
uma nova posição num contexto econômico/social atualizado e muito diferente, o menino de um ponto de vista marginal, porém, sem se vitimar, busca construir uma identidade própria, mantendo a imagem idealizada do tio. Revisitar o passado implica em obter maior autonomia para o futuro, o presente é estruturado pelo passado, através de crenças e sentimentos coletivos partilhados.

Eu nada ouvia. Ouvia sim aquele som difuso e melancólico que vinha das barrancas do rio depois da chuva, cantos dos grilos, coaxar de rãs e o rumor do rio nas paredes do seu leito. Mas o tio estava à espreita, dir-se-ia que, além de ouvir, até cheirava (FARACO, 2011, p. 49).

Por meio da referida narrativa, Faraco apresenta o herói antagônico, a figura do gaúcho como homem que não está nem aqui, nem lá, mas decifra as impossibilidades de mudar a realidade.

Ele continuava preocupado e não era por nada. Estávamos precisados de que tudo desse certo. Fim de ano, véspera de Natal, uma boa travessia, naquela altura, ia garantir o sustento até janeiro. Mas estava escrito: aquela travessia se complicava (FARACO, 2011, p. 48).

\section{As vivências}

Conforme mencionado introdutoriamente, o ensaio propõe uma aproximação entre arquétipos presentes nos contos, buscando em sua dimensão poética, potências para pensar a experiência das crianças que os narram. Desse modo, observa-se uma contribuição significativa à compreensão da condição humana através do ato de garimpar a natureza humana das personagens.

A emoção imaginativa que as crianças vivenciam nos contos através do contato com a natureza nos projeta para um olhar que flagra as experiências humanas através do imaginário de João Simões Lopes Neto, Guimarães Rosa e Sérgio Faraco, transformando o cenário natural em estado de sensibilidade. É 
possivel inferir que os fatos são apresentados por meio de uma visão de mundo bastante calcada na infância e os enredos se constituem pela compreensão típica de sujeitos que se surpreendem e se envolvem com a conjuntura que os circunda, instituindo um universo ficcional sob a ótica de sujeitos em desenvolvimento.

E a tormenta da valentia rolou, outra vez, sobre o campo.

Mas nesta hora maldita, a fumaça maldita nos rodeava e cegava; e mal íamos dando lance à carga - eu, folheirito, abanando no mais o meu bichará pra o Hilarião - rebentou na vanguarda e num flanco a fuzilaria, e vieram as baionetas... e uma colubrina, que nos tiroteavam donde não podia ser! (LOPES NETO, 1976, p. 51).

Através do espaço é possivel conhecer a imagem em sua origem, em sua essência, sua pureza, tornando as imagens e os devaneios, em intermináveis fantasias.

Sou homem de tristes palavras. De que era que eu tinha tanta, tanta culpa? Se o meu pai, sempre fazendo ausência: e o rio-rio-rio, o rio - pondo perpétuo (ROSA, 2005, p. $81)$.

A imaginação da criança comove-se com o novo que ela vê ao redor e, devido à essa sensibilidade, também vislumbra coisas novas, desenvolvendo assim a habilidade de se envolver. As vivências profundas da infância as trazem à imaginação. $O$ contato com a natureza é elemento importante para a contemplação estética na imaginação da criança, que aguça suas dúvidas, provoca temores, anuncia conflitos e os auxilia na imaginação de acontecimentos outros que os ajudam até mesmo a melhor compreender o mundo. ${ }^{25}$

${ }^{25}$ Para Edith Stein, a formação acontece tanto de modo involuntário, devido à curiosidade da natureza humana, e também voluntário, segundo o próprio empenho do indivíduo. Segundo a autora, o ser humano 'normal' traz consigo 
Foi de propósito que Tio Joca escolheu aquele dia. De madrugada já fazia jeito de chuva no céu de Itaqui e sentiase no ar aquele inchume, prenúncio de que um toró ia desabar a qualquer hora. Por toda a manhã o ar esteve assim, morno, abafadiço (FARACO, 2011, p. 46).

Segundo Bachelard o devaneio na criança é materialista, a criança é um materialista nato e seus primeiros sonhos são com as substâncias orgânicas. Torna-se evidente nas descrições o amor e a capacidade de encontrar nos pequenos espaços moléculas de mundo que permitem o vagar na narração dos autores que falam do mundo e da imensidão íntima, enviando ao leitor mensagens de reflexo que o faz tomar consciência de sua intimidade.

As crianças, presentes nos contos, possuem a necessidade de imagens, para a sua própria criação subjetiva e para a exploração estética e afetiva do mundo, caracterizando a temática central da sua vida imaginativa, alimentada por imagens novas. Os contos nos possibilitam enxergar a realidade das crianças, para que seja possível visualizar os detalhes da narrativa é fundamental a descrição cenográfica, disso depende a sensação física sugerida e o entendimento do fascínio das crianças pelas figuras do pai, do tio e do padrinho.

Mas, então, ao menos, que, no artigo da morte, peguem em mim, e me depositem também numa canoinha de nada, nessa água, que não pára, de longas beiras: e, eu, rio abaixo, rio a fora, rio a dentro - o rio (ROSA, 2005, p. 82).

um senso natural por aquilo que é justo, tanto pela objetiva quanto pela subjetiva ordem legal e moral do mundo. A humanidade tem, de acordo com os pressupostos de Tomás de Aquino, uma propensão natural que é do mesmo modo posse proveniente do espírito como os princípios do conhecimento que advém do remorso, da consciência da falta, do pecado e do arrependimento (STEIN, 2003). 
A tentativa de enxergar heróis nessas figura fragilizadas, traz o drama essencial entre si mesmo e o mundo. O exterior só é entendido quando transformado em interior, o homem ao depararse com a imensidão transforma-a em intimidade, assim não é possivel atingir o imenso senão pelas experiências.

[...] uma brisa começou a soprar, em seguida virou vento e o vento ventania. De repente parou, como param os cavalos, com os músculos tensos, na linha do partidor (FARACO, 2011, p. 47).

Quando se lê um texto literário, a imagem construída através dele tem significado em si mesma, no momento presente e de maneira distinta para o leitor, como afirma Gaston Bachelard (2002). A poesia e o devaneio são elementos importantes para fixar, para cada imagem, seu peso de devaneio interno, descrevendo uma vida pela morte. $\bigcirc$ não ser e ser nesse entre-lugar de contradição e ambiguidade em que os heróis admiram a coragem mas também fogem.

E cantou o ferro... e choveu bala!...

O meu padrinho levantou na rédea o azulego: e de espada em punho, o chiru, com uma lança de meia-lua - e eu entre os dois, enroscadito no meu bichará - nos botamos ao grosso do redemoinho, para abrir caminho para o quartelgeneral do dito Barbacena.

Como lá chegamos, não sei. (LOPES NETO, 1976, p. 50).

Acompanhamos o devaneio do pai que alimenta a imaginação com a imagem de um rio em três margens, a busca pela sobrevivência do tio forte na fronteira e os tempos de guerra do padrinho que morreu lutando, os três evidenciam uma característica da imaginação dessas crianças que se envolvem com o arquétipo do herói romântico, capaz de situar-se para lá dos limites da vida real encontrando estímulos através de seus medos. 


\section{Regionalismo e Universalização}

Tanto Simões, quanto Rosa e Faraco fazem referências particulares aos seus heróis, delineando arquétipos universais da condição humana, porém estabelecendo relações para dentro e para fora de si mesmos com aspectos ficcionais e não ficcionais. São aspectos nos quais encontramos um documentário da vida bélica, do herói que tem que cumprir o seu destino, o herói descrito através da solidão, da dor e do desamparo de um devaneio do sertanejo que viveu numa canoa e a representação e legitimação desses antepassados que lutaram pela sobrevivência, modelos para gerações futuras de um passado cristalizado.

Segundo diversas correntes teóricas, a persuasão daquilo que é regional adota um posicionamento de resistência em confronto a um modelo marcadamente centralizador de estabelecimento de uma cultura, de uma nação. José Clemente Pozzenato vem dedicando alguns de seus estudos a discutir as relações entre o regional e o universal na literatura, a começar pela transcendência do localismo bem como pela proposição de uma visão mais universal acerca dos temas.

Em conformidade com o que defende o autor, se, do ponto de vista literário stricto sensu, aquilo que é regional está subsumido ao particular e atrelado à procura pela universalidade de maneira metonímica, é necessário assumir que existe um caráter ideológico acoplado às condições culturais, históricas, filosóficas e sociais que impulsionaram aspectos que manifestaram movimento de resistência entre particular e totalidade.

Essa resistência torna-se mais evidente pelo fato de que cada povo, por meio de seus costumes e tradições, busca expressar, ao seu modo, uma perspectiva do humano. Entretanto, nem toda manifestação é bem aceita, uma vez que a visão mais centralizada de cultura contribuiu e ainda contribui para criar a estigmatização que essa mesma política centralista tem empenho em conservar para assegurar os seus propósitos de hegemonia cultural (POZZENATO, 1974). 
Uma das maiores influências de Pozzenato é a teoria de Bourdieu - para quem "região é o que está em jogo como objeto de lutas entre os cientistas [...] geógrafos [...], historiadores, etnólogos e, sobretudo desde que existe uma política de 'regionalização' e movimentos 'regionalistas', economistas e sociólogos" (1989, p.18). Considerando tal intencionalidade na diferenciação entre o que é regional e o que é universal, Pozzenato defende que toda obra literária que se pretende universal "é sempre situada com relação a um lugar, real ou imaginário, e datada com relação a um tempo, também real ou imaginário" (1974, p. 15). Desse modo, a radicalidade desses conceitos também é melhor compreendida por meio da mimeses. $\mathrm{O}$ regional, em confronto com o "universal, é uma forma do particular e deve ser subsumido por este último termo, que caracteriza um dos elementos do processo metonímico que leva, do particular ao universal, o sentido de um determinado universo literário" (1974, p. 17). Movimento esse que não esta descolado das disputas dos sujeitos pelo poder de estender sua concepção em função das memórias individuais por meio da literatura.

Para outros críticos essa oposição carrega um significado diverso: o de composição. De modo que o regional não estaria em confronto com o universal e sim que aquele colabora para a constituição deste. Para Romero, por exemplo, não se trata de dividir a literatura nacional em várias; "é apenas afirmar a unidade na multiplicidade" (1953, p. 172). Em tal processo dialético há que se dar relevância para a comprovação de identidades interiores, todavia, há que se considerar o movimento causado pelas discrepâncias vindas de outros lugares.

A partir desses pressupostos, a própria compreensão do conceito de "região" começa a ser revisitada. De modo que se torna necessário compreendê-la como dinâmica de um processo, em que a relação entre região, espaço e representações, subsumidas no texto e nas demais manifestações culturais, reflita as diversificadas formas de representação - inclusive porque todo texto literário possui um tempo e um espaço estabelecido e toda produção 
cultural está vinculada a uma região. "Uma região, assim, prefigura, compartilhando, uma das premissas básicas do Comparativismo, que afirma a arbitrariedade dos limites e a importância das zonas intervalares" (SANTOS, 2008, p. 28).

Desse modo, os três autores aqui referenciados contribuíram para tornar frequente e tradicional o movimento considerado pela crítica como universalização de temáticas regionais, conferindo às obras características filosoficamente alegóricas (BENJAMIN, 2009), capazes de abordar a profundeza do ser, que ultrapassa o caráter pitoresco mais local e torna o hibridismo e a fronteira ainda mais relevantes.

É nesse sentido que a fronteira se torna o lugar a partir do qual algo começa a se fazer presente em um movimento não dissimilar ao da articulação ambulante, ambivalente, do além que venho traçando: Sempre, e sempre de modo diferente, a ponte acompanha os caminhos morosos ou apressados dos homens para lá e para cá, de modo que eles possam alcançar outras margens... A ponte reúne enquanto passagem que atravessa (BHABHA, 2003, p. 24).

Entretanto, ainda que grande parte da literatura regional se queira universal, há que se considerar uma espécie de enfraquecimento do aprofundamento da dimensão subjetiva e individual que a obra caracterizada pela regionalidade carrega consigo. A força poética presente na obra nela é, de certo modo, alimentada por um páthos da longitude, da separação, perante o coletivo, perante o universal. Um dos motivos do potencial da experiência estética da obra literária regional reside também no fato de ela se distinguir do universal através da particularização daquela cultura.

Pensando pela vereda adorniana da Dialética Negativa (2009), é possível ponderar que a mediação enfática - que também ocorre por meio da recusa de qualquer objetividade daquilo que já carrega o status de universal - faz da experiência estética um movimento mais substancial e legítimo, podendo ser 
alcançada sua singularidade de modo mais autêntico e sensível. Isso porque, em uma via de mão dupla, em que pese o universal ser compreendido como o espaço de objetividade histórica, ele também configura um espaço de reificação e domínio (ADORNO, 1982), que endossa, apoia e apresenta seu processo organizacional como sinônimo de progresso, uma construção histórica benéfica para a área da literatura.

Desse modo, o universal se constitui historicamente a partir de uma ideia de totalidade que, de certo modo, é ancorada em uma racionalidade ideológica e socialmente constituída, uma vez que decide acerca da permanência ou não de aspectos que formam a multiplicidade e da conservação das contradições que vigoram em cada particularidade subjetiva. Decisão essa que, conforme defende Achugar, também "depende de quem fala e, sobretudo, a partir de onde fala” (2006, p. 85).

Não há aqui a intenção de dizer que toda obra regional está fadada à imediatidade quando considerada universal. Diferentemente disso, há a ponderação da possibilidade de uma cristalização de determinados aspectos e, desse modo, de um enfraquecimento daquilo que lhe difere das demais. Pois esse movimento de universalização acaba, por vezes, absorvendo as estações de reflexão que a distância, o confronto (ADORNO, 2009) e o esforço tenso do conceito (HEGEL, 2005) proporcionam. Por vezes, esses são atenuados em nome de uma tentativa de composição, enquanto partícipe da dita multiplicidade do universal, castrando a potência do ato de perambular nos caminhos ainda incertos da compreensão da obra literária, ato esse que é forçoso para o enfrentamento de si no outro.

O que necessita de desconfiança é que se tenha, através do processo da disseminação do discurso universal da literatura, uma produção cultural homogênea. Pois, seja qual for a região da qual advenha a obra literária, ela traz consigo os pressupostos colocados pela questão filosófica que discute o sujeito e a maneira como ele se relaciona com o lugar e com a cultura. Logo, as diferenças e heterogeneidades não são meramente acolhidas nesse processo que 
se queria dialético, como consequência, elas são também obsoletas e corrompidas em nome de uma tentativa de sintese do universal, que se justifica pela consternação e pela necessidade constituída e imposta historicamente por esse processo universalizante de descoberta de um eu maior literário.

\section{Referências}

ACHUGAR, Hugo. Planetas sem boca: escritos efêmeros sobre arte, cultura e literatura. Trad. Lyslei Nascimento. Belo Horizonte: Editora UFMG, 2006.

ADORNO, Theodor Wiesengrund. Teoria Estética. Tradução de A. Morão. Lisboa: Martins Fontes, 1982.

. Dialética Negativa. Rio de Janeiro, Zahar, 2009.

BACHELARD, G. A água e os sonhos: ensaio sobre a imaginação da matéria. São Paulo: Martins Fontes, 2002.

BHABHA, Homi K. O local da cultura. Trad. Myriam Ávila et al. Belo Horizonte: Ed. UFMG, 2003.

BENJAMIN, Walter. Passagens. Belo Horizonte: Editora UFMG, São Paulo: Imprensa oficial do estado de São Paulo, 2009.

BOSI, Alfredo. História concisa da Literatura Brasileira. São Paulo: Cultrix, 1994.

BOURDIEU, Pierre. O poder simbólico. Lisboa, Difel/Rio de Janeiro, Bertrand Brasil, 1989.

FARACO, S. Contos completos. Porto Alegre: L \&PM, 2011. 
HEGEL, GWF. Fenomenologia do Espírito. 3. ed. Petrópolis: Vozes, 2005.

LOPES NETO, J. S. Contos Gauchescos. Porto Alegre: Globo, 1976.

POZZENATO, José Clemente. O regional e o universal na literatura gaúcha. Porto Alegre: Movimento, 1974.

ROMERO, Silvio. História da Literatura Brasileira. 5a Ed. Rio de Janeiro: Livraria José Olympio Editora, 1953, 5 v. [1888]

ROSA, J. G. Primeiras Estórias. Rio de Janeiro: Nova Fronteira, 2005.

SANTOS, Paulo Sérgio Nolasco dos. Fronteiras do local: roteiro para uma leitura crítica de regional sul-mato-grossense. Campo Grande-MS: Ed. UFMS, 2008.

STEIN, E. Sobre el concepto de formación. In: Obras completas: Escritos antropológicos y pedagógicos. V4. Tradução de F. J. Sancho. Madrid: Ed. de Espiritualidad, 2003.

ZILMERMAN, R.; MOREIRA, M. E.; ASSIS BRASIL, L. A. (Orgs). Pequeno dicionário da literatura do Rio Grande do Sul. Porto Alegre: Ed. Novo Século, 1999.

Recebido em 06 de abril de 2017.

Aprovado em 05 de julho de 2017. 